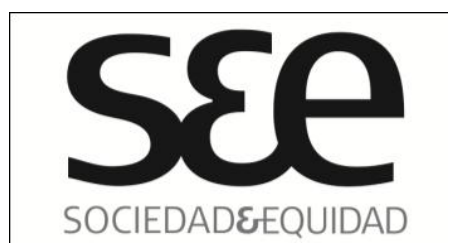

Resumen

\title{
Esperanza, decepción y anomia en los hijos de la dictadura
}

\author{
Nombre: José Luis Riquelme $(*)$ \\ Universidad: Universidad Andrés Belllo \\ Ciudad: $\quad$ Santiago \\ País: $\quad$ Chile \\ Correo:_josel.riquelme@uandresbello.edu
}

Este artículo estudia cómo y porqué un grupo no despreciable de jóvenes de Santiago, entre los años 1973 y 2000, terminan sus vidas como drogadictos, esto porque después de luchar contra la dictadura, sienten gran desesperanza, debido a la reconfirmación del neo - liberalismo, entre otras razones. Una vez comenzada la transición a la democracia, la problemática existencial de los "hijos drogadictos de la dictadura" surge de su inadaptación al discurso construido desde el poder, constituyéndose como una singular cultura urbana que ha sido siempre abordada por miradas que desconocen las sensibilidades propias de los drogadictos. Por lo mismo este trabajo pretende escudriñar en la profundidad de este universo lleno de rituales, códigos y simbolismos que son su expresión más visible e incomprendida.

\section{Palabras claves}

Drogadictos, hijo de la dictadura, violencia, exclusión, discurso.

\section{Hope, disappointment and anomie in the disctatorship' s son}

This article studies how and why young people from Santiago, between 1973 and 2000, end their lives as dredging because after fighting against the dictatorship, they feel hopeless, mainly because of the neo - liberalism among other reasons. The article proposes that the political system and the social order after 1990 did not have a space for this group so they isolate in their own world, empty of sense for society who ignore their expectations. It sought to understand their rituals, symbols and codes which are the visible expression of these uncomprehended group.

\section{Keywords}

Dredging, dictatorship son, violence, exclusion and speech.

( )El autor es estudiante de postgrado de la Universidad Andrés Bello, Docente Carrera de Pedagogía en Historia y Geografía del Instituto Profesional Valle Central. 


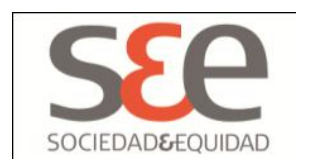

\section{Introducción}

El propósito de esta investigación ha sido descubrir el origen y analizar el discurso que conforma y modela la cultura de un grupo específico de adictos marginales del Santiago de Chile de fines del siglo que recién ha concluido, "Los hijos drogadictos de la dictadura" (Sujetos que siendo muy jóvenes o adolescentes en la etapa final del gobierno militar, no conocían otro escenario social que no fuese el de la dictadura, protagonistas activos de la jornadas de protesta del periodo 1983 - 1987, idealizadores de la democracia en la década del ochenta y devenidos en drogadictos en la década del noventa).

La génesis del creciente número de individuos que integran esta singular cultura, está entrañablemente relacionada con la utilización abusiva de violencia política, empleada desde el Estado, sobre los pobladores de Santiago de Chile en el transcurso de la década de los ochenta y en especial en su segmento más joven, "Los hijos de la dictadura". Para una comprensión más exhaustiva de esta problemática, la de la existencia de una gran cantidad de sujetos con conductas anomicas ${ }^{1}$, sobre todo jóvenes, ha sido necesario indagar en la época en la cual los pobladores santiaguinos ofrecían una tenaz resistencia a la dictadura militar liderada por el General Pinochet.

Las veintidós jornadas nacionales de protesta surgidas entre 1983 y 1987 dejaron en evidencia la existencia de una cuota significativa de jóvenes pobladores, que se rebelaban masiva y popularmente, reaccionando en contra de la violencia de Estado aplicada por los aparatos represivos del régimen militar, mostrando, de este modo, una gran capacidad de organización. Estos sujetos, los "hijos de la dictadura", desde su resistencia al régimen, habrían generado grandes anhelos y expectativas en torno a las condiciones de vida que podrían surgir a partir del término del gobierno militar. Estos sueños no fueron tomados en cuenta, en los últimos años de la dictadura, por los que iban a ser los futuros gobernantes del país, que en esos momentos pactaban la transición a la democracia con el régimen de Pinochet dejando fuera a los actores sociales considerados más conflictivos, asegurando de este modo, la "gobernabilidad" del país, lo que también se constituyó como aplicación de violencia política sobre este grupo social, y generando tras su utilización las conductas anómicas antes mencionadas.

Para dar fuerza y sustento a la propuesta planteada en este trabajo, se ha buscado apoyo en trabajos realizados por los historiadores Gabriel Salazar y Julio Pinto como también por el sociólogo Eugenio Tironi, los cuales son una gran contribución en el análisis del fenómeno de los pobladores, de su participación en las jornadas de protesta y de la posterior exclusión de estos en la salida pactada hacia la democracia.

La proposición inicial de este escrito no hubiese sido defendible sin el imponderable testimonio oral de pobladores que fueron testigos directos de estos eventos, sólo en la memoria de ellos, de los jóvenes pobladores "hijos de la dictadura", se atesoran aún las percepciones y sentimientos vividos en la cruda realidad de los años ochenta, por este motivo de un total de cuarenta y dos

\footnotetext{
${ }^{1}$ Durkheim postuló que la anomia o anomía es el mal que sufre una sociedad a causa del desequilibrio económico o al debilitamiento de sus instituciones, y que implica un bajo grado de integración por parte de sus damnificados (Merton, 2002).
} 


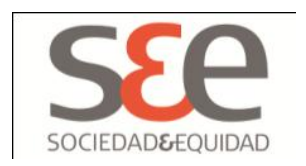

sujetos, entrevistados en el invierno del año 2010, todos ellos hijos drogadictos de la dictadura, de diferentes poblaciones de Santiago, se ha seleccionado para llevar a cabo este articulo, la voz de tres de estos individuos por ser sus discursos, de los más representativos del grupo cultural en cuestión, a los ojos del autor de este apartado. Como una forma de comprobar su validez como medio de construcción histórica, en el análisis de estos relatos se han empleado indicaciones metodológicas, referidas a trabajos con la memoria, aportadas por el filósofo y antropólogo francés Paul Ricoeur, las cuales han sido apoyadas por los enfoques teóricos, en lo que a violencia se refiere, encontrados en el trabajo de González Calleja La violencia en la política" (González Calleja, 2003), así como también en el ensayo de Enzensberger El perdedor radical (Enzensberger, Hans Magnus, 2007).

Teniendo en cuenta que la violencia ha sido siempre un componente vertebrador de las relaciones sociales y políticas de la región, no era de extrañar, que en el contexto de la dictadura militar chilena, liderada por el General Pinochet, fuese este mecanismo, el de la violencia, el que encauzó el curso político del país, desde sus inicios en 1973 y hasta su fin en 1990, teniendo consecuencias que se arrastran hasta bien avanzado el siglo XXI. Resulta, entonces, por lo menos anecdótico que "entre las muchas paradojas que ofrece este siglo está la escasa tendencia de la teorización política contemporánea (incluida la democrática) a reflexionar sobre las causas, los efectos y las consecuencias ético - políticas de la violencia" (González Calleja, 2003: 21).

Entonces, la pretensión básica de este escrito, en su primera sección, que lleva por nombre Esperanza, Decepción y Anomia en los Hijos de la Dictadura, será la reflexión en torno al modo bajo el cual, por un lado, el uso de la violencia, personificada en la utilización de la fuerza por parte de los organismos de represión y coacción del Estado en contra del movimiento popular, representado en la década de los ochentas por los pobladores, tuvo como respuesta por parte de estos actores sociales una enérgica resistencia, cuya máxima expresión fueron las veintidós jornadas de protestas nacionales que se sucedieron entre 1983 y 1987. Por otra parte, se busca evidenciar cómo en este largo periodo de luchas sociales los jóvenes pobladores capitalinos, principales protagonistas de estos sucesos, mostraron un alto compromiso con la posible transformación del sistema político - social en curso. En una última instancia, esta sección ha buscado demostrar cómo, a partir de la medianía de la década de los ' 80 , el movimiento popular será objeto de empleo de otra táctica de violencia política, en esta ocasión escenificada por la exclusión de los pobladores, de la discusión política que comenzaba a entramar el gobierno militar con la clase mesocrática, lo que tuvo como efecto, una vez iniciada la llamada transición a la democracia, la reconfirmación del modelo neoliberal instaurado por el régimen militar, incidente muy trágico para un gran número de individuos que habrían forjado conductas anomicas hacia el sistema en curso, convirtiéndose muchos de ellos en jóvenes pobladores drogadictos.

Una vez comenzado el periodo de transición a la democracia, y conocido el origen del aumento de la drogadicción entre los jóvenes pobladores de Santiago, la problemática existencial de los "hijos drogadictos de la dictadura" va a surgir a partir de su rebeldía e inadaptación al discurso construido desde el poder en el transcurso de la modernidad.

La notoriedad alcanzada por esta peculiar cultura urbana, ha sido siempre abordada por miradas de autores que desconocen las sensibilidades propias de los drogadictos, por lo mismo este trabajo ha pretendido escudriñar en la profundidad de este universo lleno de rituales, códigos y simbolismos que son su expresión más visible e incomprendida. En este punto en particular, el de conocer el origen y significado de estos rituales, códigos y simbolismos, resulta muy útil el apoyo brindado por Norbert Elías en El proceso de la civilización, ya que presta ayuda para aproximarse 


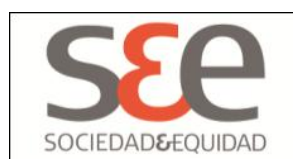

al conocimiento de las motivaciones bajo las cuales un sujeto nacido y formado en el orden moderno se convierte en el devenir de su vida en un drogadicto marginal.

Otro intelectual que otorga un fuerte sustento al descubrimiento del origen de la existencia de los jóvenes pobladores drogadictos es el filósofo francés Pierre Bourdieu, al amparo de su teoría de la reproducción cultural, se puede establecer la manera bajo la cual se lleva a cabo el traspaso generacional de la drogadicción.

Como ninguno de los autores antes mencionados han tratado en sus trabajos respectivos, en forma directa, el problema de la drogadicción se ha hecho necesario trabajar con fuentes orales para lo cual se han entrevistado a individuos pertenecientes a esta cultura, utilizando la metodología aportada por Paul Ricoeur, en "Historia y memoria". Por lo mismo el abordaje de los sujetos entrevistados, en este trabajo investigativo, es desde un enfoque cultural, no habiendo ninguna intención de un estudio de la retorica de los involucrados en él. Por ello se ha apelado a la noción de reminiscencia en la búsqueda de esa remembranza que solo puede ser rescatada desde la memoria de estos individuos, verdaderos y únicos protagonistas de esta historia.

¿Por qué jóvenes que lucharon contra la dictadura al momento de iniciarse el primer gobierno civil no asumieron el consumo de drogas como alternativa? ¿Por qué algunos de estos/as se mantuvieron en la lucha social y otros/as la abandonaron? Son interrogantes que podrían dar luces de la cuna del devenir en drogadictos, de los sujetos que aquí son objeto de investigación de una forma más certera. Lo cierto es que este escrito se enmarca dentro de una investigación mayor y en otro de sus segmentos de estudio se está indagando a partir de características psicológicas de su personalidad, la razón por la cual son propensos a la práctica de la drogadicción.

En resumidas cuentas lo que aquí se pretende es mostrar una parte de la historia de los "jóvenes drogadictos hijos de la dictadura" del Santiago de Chile de fines del siglo XX de una manera distinta, demandando la cuna de su problemática, desde adentro de su propia cultura, en contraste con la habitual mirada del discurso oficial propiciado desde el poder.

\section{Esperanza, Decepción y Anomia de los Hijos de la Dictadura}

El golpe de Estado propinado por las fuerzas armadas el 11 de septiembre de 1973, impacto en tal magnitud al "movimiento social - popular" ("El concepto alude a "movimiento", "acción", "actividad", supone que los actores históricos (en este caso, los sujetos populares) se movilizan con el objeto de transformar una realidad considerada adversa o, por lo menos, problemática" ) (Salazar y Pinto, 1999: 97), que todas sus mejoras y reivindicaciones sociales quedaron sepultadas por la violenta instauración de un orden neoliberal. De esta manera la aplicación de violencia política, ejercida por el gobierno de las fuerzas armadas, hacia los sujetos populares, se habría presentado en pro de generar un proceso refundacional del capitalismo.

Esta transformación, por supuesto, no fue bosquejada, ni llevada a cabo únicamente por los oficiales golpistas, sino que habría sido diseñada por sectores dirigentes del capitalismo criollo. "Puesto en marcha bajo el férreo auspicio de la Dictadura militar, el proyecto de refundación neoliberal se inspiró y desplegó gracias a la iniciativa y la conducción directa de sectores de esa propia elite, que venían preparándolo a lo menos desde fines de la década del cincuenta" (Salazar y Pinto, 1999: 57). Visto así, a comienzos de la década de los '70 el diálogo fue abandonado como modo de interlocución política, por parte de las elites económicas del país, optando por un 


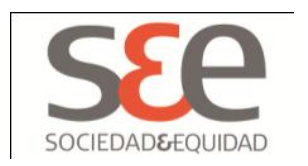

"original" proceder comunicacional, la utilización de violencia en contra del movimiento social popular partidario del gobierno de la Unidad Popular.

"En realidad, la violencia no puede interpretarse nunca como falta de comunicación, sino como un modo especial de intercambio social; asimétrica, es cierto, pero que impone un intercambio y presupone una respuesta..." (González Calleja, 2003: 44). En el transcurso de la Dictadura militar, esta respuesta fue vedada desde el Estado por sus aparatos de represión, que perseguían, apartando de su camino, a todos los sujetos que intentaran obstaculizar el curso establecido por esta, primando en el periodo 1973 - 1980, sensaciones de consternación y desaliento entre los pobladores.

"La crisis económica de 1982 acalló los cantos de sirena del neoliberalismo y gatilló, en la sociedad civil (y en el mundo poblacional en particular), resistencias que hasta 1983 se habían mantenido ocultas" (Salazar y Pinto, 1999: 125). Al comenzar el decenio de los ochentas se produjo un punto de inflexión en las relaciones de violencia establecidas entre el Estado y los pobladores capitalinos, siendo la debacle económica del '82 la que agregada a la creciente deslegitimación del proceder de los organismos de seguridad del gobierno militar, que en esta época irrumpían reciamente, allanando las poblaciones capitalinas más populares, la causal del inicio de las llamadas jornadas de protesta nacional del periodo 1983 - 1987, las cuales se legitimaron al constituirse en actos de insurrección popular levantados en defensa de la dignidad humana de los pobladores, ante una institucionalidad que utilizaba la fuerza de modo arbitrario e ilegítimo, por lo mismo, el uso de violencia insurreccional, por parte del movimiento social - popular fue legítimo.

La gran diferencia del movimiento de los pobladores de la década de los ochenta con sus predecesores de los dos decenios anteriores, gravita, en que la coordinación de sus acciones no estaba instrumentalizada por ningún partido político, es más el movimiento en sí fue autoprocreado desde sus bases, y en ello tuvo gran responsabilidad, el uso de violencia política por parte de la Dictadura;

El Problema de fondo parecía ser, hacia 1983, que la desclientelización de la clase popular autoinducida tanto como forzada - con respecto al Estado, las normas constitucionales, los partidos políticos y aun con respecto a las cúpulas sindicales, era tal, que la función cupular estaba orgánicamente reducida a una tarea transmisora de recepción - emisión, orgánicamente acoplada al movimiento social, y a poco o nada más. La percepción popular de la dictadura era de por sí clara y estaba demasiado encarnada: no se necesitaban ni explicaciones teóricas adicionales ni vanguardismos superfluos

(Salazar, 2006: 298)

Los canales de comunicación habituales estaban rotos y las normas comunes de comportamiento político del movimiento social popular no existían, en cierto modo el gobierno militar con su actuar represivo y de "tolerancia cero", hacia todo lo que oliera a oposición marxista, obligó a los pobladores, ante la ausencia e inoperancia de los que antes habían sido sus antiguos dirigentes, a una reorganización instituida desde sus propias bases con el objeto de combatir la dictadura. En 


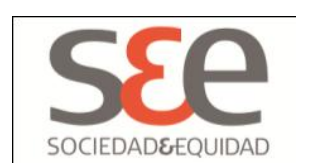

este sentido las agresiones perpetradas desde el Estado habían fracasado en su afán de destruir al movimiento social de los pobladores, y por el contrario habían generado, en él, un grado importante de cohesión y esperanza en torno a lo que podría lograr.

Cada sujeto se sentía legítimamente instalado sobre la primera piedra en el proceso de construcción de un nuevo Estado. La distribución simultánea de esas percepciones y predisposiciones a todo lo largo y ancho de la sociedad popular era un hecho fácilmente intercomunicable de un grupo a otro o de una región a otra. Es decir: estaban a punto (sincronizados) todas las percepciones y sentimientos que normalmente han animado o motivado, en la historia de Chile, al movimiento social popular cuando ha estado en trance de entrar en acción. De modo que, ¿para qué las cúpulas, sino para dar arranque nacional a toda esa carga histórica?

(Salazar, 2006: $298-299)$

El problema es que todo ese peso histórico sería obviado por la clase mesocrática, en el periodo final de la dictadura, lapso en el cual transaba la salida consensuada del gobierno militar hacia la convivencia democrática, con los altos personeros del régimen autoritario.

La novedad más significativa, aquí, fue la existencia, de un gran número de actores sociales, los pobladores, que percibían, gracias al ambiente propiciado en torno a las jornadas de protesta, en el seno de sus poblaciones, sentimientos de ser protagonistas trascendentes en el desarrollo político del país, por lo que abrigaban, muchos de ellos, esperanzas y anhelos en torno a lo que sería un futuro gobierno democrático. Al interior de este grupo social es necesario poner acento en sus componentes más jóvenes, "Ios hijos de la dictadura", los cuales nacidos bajo el régimen militar, solo eran conocedores del deprimente escenario instaurado por éste, y por lo mismo vislumbraban magnas expectativas en lo que sería el retorno a la democracia, idealizándola, tal vez, en forma desmesurada.

Con objeto de lograr una percepción más acabada, de estos sentimientos de esperanza cobijados por "los hijos de la dictadura" esta investigación se ha remitido a trabajos con la memoria, de sujetos pertenecientes a este grupo, que durante la década de los ochenta habitaban poblaciones marginales de Santiago. Con respecto al empleo de este tipo de fuentes y su validez histórica, Paul Ricoeur es categórico al enunciar que;

A la memoria le queda la ventaja del reconocimiento del pasado como habiendo sido, aunque ya no lo es; a la historia le corresponde el poder de ampliar la mirada en el espacio y el tiempo, la fuerza de la crítica en el orden del testimonio, explicación y comprensión, el dominio retórico del texto y, más que nada, el ejercicio de la equidad respecto de las reivindicaciones de los distintos bandos de memorias heridas y a veces ciegas a la desgracia de los demás 


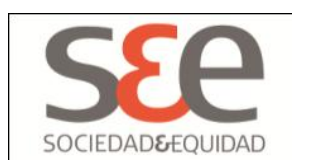

(Ricoeur, 2000).

De este modo el testimonio otorgado por estos jóvenes pobladores "hijos drogadictos de la dictadura", se transforma en un objeto de análisis consustancial a la hora de conocer las reales sensibilidades concebidas al interior de los corazones de estos sujetos, ya que estas percepciones solo pueden ser trasformadas en escritos a través de sus voces, no existiendo, dato estadístico, ni documento oficial que dé cuenta de tales emociones. Estos sentimientos están vivos aún, en la memoria de Miguel, adolescente poblador de una comuna del sector sur de Santiago en los años '80, quién ante la sola mención de las jornadas de protesta del periodo 1983 - 1987, deja entrever, todo un mundo de sensaciones y emociones:

¡Sí!, absoluto, clarísimo el primer cacerolazo a nivel nacional, con corte de luz incluido, con los primeros rayados que vi en esa época, en los llamados a la huelga, cierto, cuando volvían a renacer las primeras brigadas de los partidos de las juventudes, la BRP, la Luis Emilio Recabarren, sí, increíble, y el nacimiento posterior de todos aquellos movimientos que impulsaron la lucha callejera en jornadas bastante ajetreadas, porque comenzaban con los cortes de luz, con los cacerolazos, después venían los enfrentamientos, bueno ese fue también parte de la educación de uno, formación popular sin duda, con un saber que entregaba la calle, con el saber que las poblaciones tenían mística, en que el vecino creía en el vecino y que desconfiaba de quién tenía que desconfiar y sabía de quién tenía que desconfiar, pero que tenían harta mística una unión, que podríamos decir, hasta mágica en términos de que había una adversidad muy tremenda, que había un enemigo tremendo, que arrasaba y que sin embargo, a pesar de eso que podía generar temor, cierto, y arrasar con esa necesidad que tiene el ser humano de crecer y de ser libre, y sin embargo, nos unía aún más, en torno al objetivo, que era derrocar a Pinochet, porque en eso creíamos, y en eso soñábamos, en un mundo más igualitario tras su caída

(Joven de la población El Silo, 36 años)

Para Paul Ricoeur, "el recuerdo de la cosa no se da ni siempre ni frecuentemente, es necesario buscarlo" (Ricoeur, 2000), pero en el caso de este joven poblador, la anámnesis o reminiscencia en el recuerdo se da por sí sola y en su discurso se puede percibir una noción por parte de este sujeto de ser una pieza importante en el andamiaje histórico del tiempo evocado en su relato, dejando entrever, en él, sentimientos tan disímiles como son la confianza y la desconfianza o el temor y la esperanza, pero delatando en el trasfondo de sus palabras la sensación final de estar viviendo una época de gran expectación, un momento decisivo en definitiva.

A partir de la reactivación económica del año 1984, y ante la activa resistencia ofrecida por el movimiento social - popular, la Dictadura Militar, establece dispares modos en su trato a la oposición según fuese el origen de la misma. Con la clase mesocrática dio inicio, a un tímido diálogo político, pero diálogo al fin, que tendría como resultado final, la salida pactada hacia la 


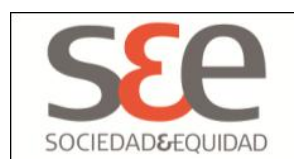

democracia. En cambio, con el movimiento de los pobladores, siguió su escalada represiva, pero con la diferencia que ahora contaban, los aparatos de seguridad de la dictadura, con el apoyo de la clase mesocrática que lumpenizaba la lucha insurreccional brindada por los pobladores santiaguinos, de esta forma el uso de la violencia, como mecanismo de resistencia hacia la dictadura se fue deslegitimando a los ojos de los futuros gobernantes del país. De este modo se validaba el modelo neoliberal impuesto por la Dictadura Militar, excluyendo de toda discusión política, toda la carga histórica de esperanza y expectación, plasmada en las movilizaciones callejeras al interior de las poblaciones marginales. Pasando la medianía de década esta estigmatización (de lumpen, de vándalos, de delincuentes...) haría eco en los jóvenes pobladores "hijos drogadictos de la dictadura";

A mí me desespera que de repente nos vean como vándalos. ¿Qué alternativas tenemos? Si somos así es porque no queda otra: o nos sacamos la cresta por votar este gobierno o no sé qué hacemos. ¡No resistimos más! Hemos vivido en esta dictadura toda nuestra vida y nuestro futuro depende de que se acabe este gobierno...Yo tengo que salir a la calle porque, si no sale mi papá, ni mi mamá, ni sus amigos, si no sale nadie tengo que salir yo iporque yo no puedo seguir viviendo así!

(Joven 16 años. En Salazar y Pinto, 2002: 249)

Sería esta aplicación de violencia política personificada en la exclusión encubierta tras todo un talante de ceremonial democrático, la que aniquilaría las esperanzas de los "hijos de la dictadura". La supresión del movimiento social - popular, no fue solo, de la discusión política en que se pondría fin a la dictadura, sino también, del modo en que se le daría continuidad al modelo neoliberal fundado por esta. "El movimiento mesocrático, tradicionalmente capacitado para satisfacer tales necesidades, comenzó a elaborar sus discursos, y desde 1984 - 85 evacuó una completa teoría sociopolítica acerca de la "transición chilena a la democracia" (Salazar, 2006: 303).

La anulación del movimiento de los pobladores capitalinos del dialogo político, que supondría el retorno a la democracia, presumió penosas consecuencias entre estos actores sociales, una es el quiebre comunicacional con los futuros gobernantes antes de que estos se constituyeran como tales, dejando al movimiento social - popular una sola opción para demandar reivindicaciones sociales en el futuro, el uso de la violencia, pero la teoría socio política relativa a la "transición chilena a la democracia", estaba diseñada para contenerla. "Es históricamente significativo que esta teoría haya sostenido, entre otras cosas, que la rutinización de la protesta popular constituía una amenaza de desintegración social (considerando la "anomia" inherente a la masa poblacional), y que en Chile prácticamente no existían movimientos sociales populares" (Salazar, 2006: 304).

La clase mesocrática, que se constituiría en gobierno al comenzar la década de los '90 tenía absoluta conciencia del peso específico del cual eran poseedores los jóvenes pobladores al termino del gobierno democrático, de ello daba cuenta José Auth en 1988; "Tratándose de los jóvenes, podemos decir algunas generalidades rayanas en la evidencia, como que constituyen un electorado más progresista, que su rechazo al sistema global es mayor, que son siempre más radicales, en fin, que en el plebiscito que se avecina optarán por el No en una proporción mayor 


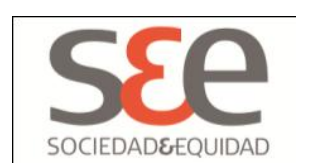

que los adultos" (Auth, 1988: 84). ¿Fue simple utilización política este conocimiento relativo a la importancia juvenil en el desenlace del gobierno militar?, o ¿fue que acaso no existía confianza en la capacidad de estos jóvenes? La respuesta la otorga el mismísimo Auth;

Nunca los jóvenes de diferentes estratos sociales habían estado culturalmente tan próximos unos de otros. Nunca antes las posibilidades de emergencia de un movimiento juvenil habían sido tan ciertas, jamás una identidad común en la cultura y en las expectativas tan posible, un adversario común tan delimitado, un proyecto unificador - la apertura de la sociedad - tan definido, y una fuerza electoral tan decisiva

(Auth, 1988: 91)

El sociólogo Eugenio Tironi daba cuenta, en 1987, en lo referente a las jornadas de protestas en las poblaciones santiaguinas, que "las movilizaciones de los marginales, se preguntan mucho, ¿hasta qué punto no son incompatibles con un tránsito pacífico a la democracia y con su consolidación?" (Tironi, 1987: 10). Tal vez lo que se debió haber preguntado, aquí, fue; ¿̇hasta qué punto las movilizaciones del movimiento social popular eran compatibles con la perpetuación del modelo neoliberal refundado a partir del golpe de Estado de 1973? y ¿si existía tanta conciencia con respecto a las movilizaciones de los marginales?, ¿Por qué se les excluyo?, ¿Por qué no se les integró en el diálogo político?, ¿o se constituirían en un grupo peligroso para la estabilidad y legitimidad de los futuros gobiernos? Más allá de responder a estas interrogantes, lo cierto es que, la instauración del modelo impuesto por los gobiernos de "Transición a la Democracia", condujeron a ciertos sujetos a caer en comportamientos anomicos hacia el sistema, de ello da cuenta el siguiente testimonio de un "joven drogadicto hijo de la dictadura":

La última etapa del régimen militar fue de alta actividad en la población, tenía una curiosidad tremenda en lo que sería la democracia, la expectativa que se forma este individuo que no conoce nada de eso, cierto, es muy alta, también hay una influencia del pensamiento que uno tiene y esas expectativas se redoblan a través de que se termina esta etapa oscura y se inicia una etapa de supuesta claridad, [...] y resulta que te das cuenta que definitivamente estuviste puro hueviando por años, yo no sé qué paso, que al cabo de un par de años el mismo compañero, que estaba contigo apedreando a los pacos, estaba en el PPD, y ese huevón ahora ni te saludaba y uno que siguió en la lucha y con los ideales terminó mal y él que se vendió está bien, hay unos sentimientos hasta de rencor sin duda [...]el punto es que ahora sigo teniendo ideales, pero como que estoy solo, ya nadie los comparte conmigo[...]yo creo que esta realidad la evadí con drogas y más encima que el acostumbramiento, tú te acostumbras te gusta, y después de un día agitado, te fumas un cuete o te tomas un trago [...]el sistema en sí anula los sueños, el capital no tiene ideología, es solo la ideología del capital, te utiliza la política como punta de lanza nada más y el que está en el poder va a 


\section{S\&e}

tener que negociar y se arreglara para mantenerse en el tiempo [...] el sistema en sí tiende a transformarte y transforma al ciudadano, ojo, al ciudadano dije, en un consumidor, entonces el consumidor de drogas no es un ciudadano consciente de su deber, de su peso específico en la sociedad como parte de un estrato social y tendemos a encerrarnos en nuestro mundillo de consumo de drogas...

(Poblador, 37 años).

Este sujeto, el mismo que, constituido en los ochenta, como una persona que abrigaba esperanzas y anhelos en torno a la recuperación de la institucionalidad democrática, término con sentimientos de frustración y desencantado con el sistema vigente. Es evidente en él la existencia de un comportamiento anomico hacia el sistema lo que se ve reflejado en un consumo abusivo de drogas ilícitas y licitas lo cual demuestra "que la violencia no siempre va hacia afuera, que a menudo nos agredimos y nos destruimos nosotros mismos, violentamos nuestro cuerpo, destruimos nuestro mundo interior." (González Calleja, 2003: 28).

Es una realidad, entre muchos de los "jóvenes drogadictos hijos de la dictadura", la concepción de conductas de desadaptación y anomia al sistema imperante, entre estas el consumo de drogas, y es evidente que, si unos años antes se hubiesen incluido, demandas del movimiento social popular en la discusión política de conformación del nuevo gobierno, estos comportamientos habrían sido menos extensivos y así, gran parte de estos jóvenes pobladores que se caracterizaban al mediar la década de los ' 80 por brindar una férrea resistencia a la dictadura y por mostrar una enérgica disposición a luchar por sus sueños e ideales, no hubiesen engrosado, muchos de ellos, una vez reinstaurada la institucionalidad democrática las estadísticas e índices de consumo de drogas.

\section{La episteme de los drogadictos marginales de los '90}

Es hermosa y múltiple la tarea que tenemos por delante, restablecer un clima de respeto y de confianza en la convivencia entre los chilenos, cualesquiera que sean sus creencias, ideas, actividades o condición social, sean civiles o militares [pifias de casi todo el público presente en el estadio], isí señores!, isí compatriotas!, iciviles y militares!, iChile es uno solo!

Abrir a nuestros jóvenes acceso a los conocimientos y oportunidades de trabajo y de progreso propias del tiempo que vivimos

$(\text { Aylwin, 1990) })^{2}$

\footnotetext{
${ }^{2}$ Extractos del discurso dado por el Presidente Patricio Aylwin a un día de haber recibido la banda presidencial de manos de Augusto Pinochet, ante un Estadio Nacional repleto, 12 de marzo de 1990.
} 


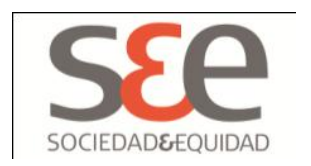

Si bien en los inicios de la década de los noventa, todos los discursos públicos efectuados por personeros de gobierno anunciaban un país con políticas de inclusión hacia todos sus sectores, la suerte de los jóvenes pobladores ya estaba echada debido a la exclusión política de la cual habían sido objeto en el último lustro de la década de los ochenta. La complicación más fiera e insoslayable que debieron afrontar los "hijos de la dictadura", fue la de enfrentar el discurso modernizador concertacionista que no daba cabida a lo que había sido la forma más familiar de expresarse para ellos en el curso de los últimos años; la protesta callejera había sido embargada del circuito político, pues todo lo que oliera a violencia atentaba con la tan anhelada democracia. Dicho de otra manera, en los noventa comenzaba a regir un sistema de gobierno que funcionaba con una democracia inclusiva en su forma (discurso externo y a viva voz) y exclusiva en su fondo (discurso interno, subterráneo, lo que realmente se hace). La clase mesocrática gobernante por un lado renegaba del pasado autoritario, represivo y violador de derechos humanos de la dictadura, pero por otro continuaba con su modelo económico, político y social; De esta manera "Silenciados los campanarios políticos, la juventud de toda extracción se dispersó en horizontal, cubriendo el territorio con grupos, redes, colectivos, carretes, barras bravas y otras expresiones de "tribalismo urbano". Llenándose a sí misma de charla y discusión, con tabaco, con alcohol, con droga" (Salazar y Pinto, 2002: 259).

La estigmatización social, el desdeño y la poca preocupación, fue la respuesta desde el poder, para tratar la problemática de una juventud cuya máxima fue el "no estar ni ahi".

Tal actitud requería de la autoridad al menos un diagnóstico. ¿Qué les está pasando? Todos se preocupan. ¿Va el diagnostico? Va. ¿Qué dice? Que los jóvenes fueron "dañados" por la dictadura y toda la convulsión social, política y económica que sufrió el país a lo largo de cuatro décadas. Que la democracia y el país tienen con ellos una "deuda social". Que se paga educándolos, capacitándolos, rehabilitándolos, empleándolos, ordenándoles (podándoles) su memoria, entreteniéndolos, etc. Pues es preciso atraerlos a la modernidad global (“ibienvenida la modernidad!” gritó, delante de ellos, un educador moderno) y olvidar que alguna vez fueron ariete de cambio, fuerza de choque y carne de cañón

(Salazar y Pinto, 2002: 259).

En definitiva, se utiliza como cura el origen de la enfermedad, reproducir su miseria mediante una educación hecha a la medida de la clase dominante, educación construida categóricamente para transformar a los jóvenes pobladores en sujetos que respeten "El orden del discurso" (Foucault, 1992), benevolente en su superficie, perverso y exclusivo en su fondo.

En lo relativo a este discurso modernizador Foucault opinaba; "Pienso que en mucha gente existe un deseo semejante de no tener que empezar, un deseo semejante de encontrarse, ya desde el comienzo del juego, al otro lado del discurso, sin haber tenido que considerar desde el exterior cuanto podía tener de singular, de temible, incluso quizás de maléfico" (Foucault, 1992: 9-10). Lo pernicioso del discurso validado por los nuevos gobiernos de la Concertación, fue que siendo en su esencia más íntima heredero del orden neoliberal fundado por la dictadura militar, en él no se podía estar en la otra vereda del discurso, no se podía ser dueño de otra verdad, a diferencia de la década de los ochenta, en donde, la episteme de los jóvenes pobladores era refrendada en su 


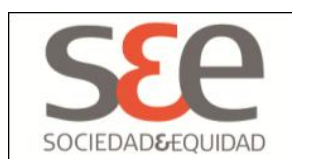

resistencia diaria al régimen autoritario y en la posibilidad de generar un contradiscurso. Una vez silenciados en su discurso muchos "hijos de la dictadura", se verán tentados a evadir una triste realidad mediante el consumo de drogas.

Loïc Wacquant, en sus escritos Cárceles de la miseria (Wacquant, 2000) y Parias urbanos. Marginalidad en la ciudad a comienzos de milenio (Wacquant, 2001) manifiesta cómo los medios de comunicación divulgan incidentes simbólicos de damnificados de la transgresión; la ley de hierro en contra del delito, y la drogadicción es planteado por prensa, radio y televisión como la única solución. Pero siendo algo más agudos se puede conseguir presentir la existencia de una verdadera edificación social del discurso sobre la delincuencia y la drogadicción. Lo cierto es que el desequilibrio del espacio público y la sociabilidad han llevado a un recrudecimiento en las condiciones de vida al interior de la ciudad.

Tanto Wacquant como Pierre Bourdieu, en su escrito Contrafuegos. Reflexiones para servir a la resistencia contra la invasión neoliberal (Bourdieu, 1999), se refieren a cómo la retracción del espacio público y del Estado social es concomitante con la ingobernabilidad del capital transnacional y el incremento de una marginalidad neoliberal visible en el desempleo, el empleo precario, la segregación y estigmatización territorial, la informalidad y la delincuencia, susceptibles de ser reguladas por un Estado penal invasor y omnipresente. De este modo la "guerra contra las drogas" y el consumo de drogas ilícitas se propaga como posibilidad cierta de ejercitar la criminalización de la pobreza y la protesta social.

En cierto modo la juventud marginal se vio desamparada y sin espacios donde vaciar todas sus inquietudes. En la última década del siglo XX ellos no podrían mantenerse ajenos al proceso modernizador neoliberal con todas sus implicancias, y entre estas el inconveniente de la drogadicción. "Como se sabe, en los últimos años, el tráfico de drogas se ha incrementado notoriamente en Chile, muy en especial, desde 1992, el de "pasta base". (Salazar, 1995: 34).

La recalada de la pasta base, va a concordar con la transformación estructural del fenómeno de la droga en el país. Chile deja de ser el típico país por el cual transita la droga en busca de otros mercados y se gradúa de nación consumidora, constituyéndose en un excelente mercado para los traficantes internacionales y una buena fuente de ingresos a numerosas familias chilenas. "La droga ha pasado a ser para muchas familias chilenas no sólo la causa de desestructuración y crisis familiar, sino también fuente de nuevos y variados ingresos económicos. Chile se ha transformado, en el curso de una década, de un país de tránsito a un país consumidor de "droga". (Pérez, Sepúlveda, Gaínza, 1997: 12)

El ingreso masivo de esta sustancia, la pasta base de cocaína, es sincrónico con la llegada de la democracia y lastimosamente, para los fragmentos más populares, en específico el de sus jóvenes pobladores, se convertirá en el síncope que aletargará sus existencias. La pasta base será la poción de los pobres por excelencia en toda la década de los ' 90 y su consumo se transformará en uno de los trastornos sociales más desdeñables en la medida que transcurre el tiempo. De este modo al mediar la década, "Todo joven es culpable antes de que se pruebe lo contrario. Doblemente culpable si se trata de un joven urbano-popular, triplemente culpable si además es pastabasero" (Pérez, Sepúlveda, Gaínza, 1997: 12).

El consumo de drogas aumentó considerablemente en el transcurso de la década y así lo corroboran las estadísticas policiales de fines de siglo. En el Anuario de Estadísticas de la Policía de Investigaciones de Chile de 1998 se puede apreciar cómo el número de aprehendidos por 


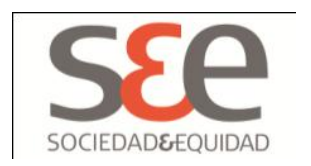

infracciones a la ley de drogas ha crecido sustancialmente en solo cinco años, siendo la cantidad de personas detenidas y puestas a disposición de los tribunales un total de 3116 . Esto constituye un $60 \%$ de aumento en las detenciones por infracción a la ley de drogas con respecto a 1993. A esto hay que agregar que el consumo de drogas es mucho más masivo que el detectado por los aparatos policiales.

A estos datos cabe agregar que del total de detenidos 2570 corresponden a personas menores de 40 años, lo que equivale a más del $80 \%$ del universo total, de lo que se desprende que el grupo más damnificado por el consumo de drogas está constituido por personas jóvenes.

También más de un $80 \%$ de los aprehendidos por infracciones a la Ley de drogas se desempeñan en actividades propias de sectores socioeconómicos medios bajos o bajos, o bien se encuentran cesantes, de lo que se puede inferir que los estratos más afectados por esta "plaga "son esencialmente populares.

Otro dato que no se debe dejar de pasar por alto es que en el año 1993 el decomiso total de cocaína y pasta base de cocaína en el país fue de 603,63 kilogramos, lo que refleja un aumento sustancial con respecto a los 91,53 de 1989 y muy por debajo de los 1437,54 del año 1998. Esta estadística deja de manifiesto un aumento sustancial en el decomiso de drogas duras, cocaína y pasta base, y un incremento gigantesco de incautaciones desde el arribo de la pasta base al país. Finalizada la década en el año 2000 la cantidad de pasta base de cocaína incautada solo por la Policía de Investigaciones será de 987,210 kilogramos (INE, 2001: 94).

Finalmente hay que señalar que si bien las estadísticas policiales no reflejan las verdaderas cantidades de drogas circulantes en el territorio nacional, ni la cantidad de adictos presentes en las poblaciones, da una noción del cuadro general y se puede concluir que al finalizar la década de los 90 se presenta un incremento considerable en el consumo de drogas, especialmente pasta base, dejando entrever, a esta realidad latente, como una de las dolencias más colosales entre los marginados del país, siendo los jóvenes pobladores los más perjudicados.

La gran cantidad de sujetos que se han visto vinculados con el uso excesivo de sustancias ilícitas con el fin de rehuir de un escenario en donde su manera de actuar no está en el libreto de "El orden del discurso", no ha pasado inadvertido por las instancias de poder existentes en el país. Por lo mismo, han sido objeto de aplicación de violencia política (nadie podría negar que no viene desde el poder). Esta vez la aplicación de esta violencia es mucho más elaborada y simbólica, no ejerciendo ningún tipo de fuerza física en contra de los afectados, sino más bien imponiéndoles los reparos a su mal de tres maneras: solución psiquiátrica, solución policial (represiva) y solución penal (cárcel). Así los jóvenes pobladores drogadictos son tildados de locos, perseguidos o encarcelados por los agentes del poder, teniendo siempre la precaución de mostrar, en su discurso, que este uso de violencia es algo legítimo y en pro del bien común. Michel Foucault ha dado cuenta de este proceder; "Yo supongo que en toda sociedad la producción del discurso está a la vez controlada, seleccionada y redistribuida por un cierto número de procedimientos que tienen por función conjurar los poderes y peligros, dominar el acontecimiento aleatorio y esquivar su pesada y temible materialidad" (Foucault, 1992: 11). Este proceder del discurso ha impuesto una sola episteme oficial que se muestra como objetiva a los ojos de la opinión pública en general, relegando y subyugando cualquier discurso que se le oponga. A esta verdad Foucault la llamaba voluntad de verdad advirtiendo con respecto a ella que "basada en un soporte y una distribución institucional, tiende a ejercer sobre los otros discursos - hablo siempre de nuestra sociedad - una especie de presión y como un poder de coacción" (Foucault, 1992: 18). 


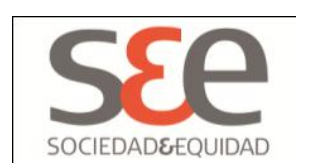

Los drogadictos marginales son sujetos pertenecientes a una cultura vilipendiada y acallada en su propio discurso, siendo la única manera de reinserción y adaptación de estos individuos excluidos del discurso modernizador, el cambio de comportamiento, es decir, el readecuar su alma, el olvidar sus sueños, el dejar de ser una persona sensible, el abandonar su propio "yo". Según Michel Foucault esta metamorfosis general en la actitud de los sujetos, algo que según él es "un cambio que pertenece al dominio del espíritu y de la subconsciencia"(Foucault, 2002: 82), no estaría perfilada en el caso de los drogadictos marginales, ni de ninguna otra contracultura, en beneficio de ellos mismos, sino más bien consistiría en un "esfuerzo para ajustar los mecanismos de poder que enmarcan la existencia de los individuos; una adaptación y un afinamiento de los aparatos que se ocupan de su conducta cotidiana, de su identidad, de su actividad, de sus gestos aparentemente sin importancia, y los vigilan; una política distinta respecto de la multiplicidad de cuerpos y de fuerzas que constituye una población" (Foucault, 2002: 82).

En este sentido la vigilancia y penalización sobre los individuos que componen esta particular cultura ha sido inclemente intentando domesticar conductas forjadas en la génesis misma del discurso dominante.

La droga ha estado siempre... en dictadura el consumo más marcado era marihuana, las otras drogas aparecen cuando desaparece el gobierno militar. Entran la coca, la pasta, las pastillas, sicotrópicos, barbitúricos, jarabes. Con el tiempo me he dado cuenta que a nosotros nos metieron la huevadita pa acallarnos porque igual hubiésemos hueviado a estos giles que nos gobiernan ahora. Yo aquí estoy consumiendo todo tipo de drogas menos inhalantes, digamos neopreno y esas manos, consumo marihuana, pasta, coca, pastillas...yo estuve internado también en el hospital psiquiátrico, también por droga y por problemas depresivos y toda la onda, y la droga es igual una enfermedad estando atrapado cuesta salir... ta de cajón que el sistema no está hecho pa un drogadicto, yo lo miro desde el punto de vista de un drogadicto y el sistema no está preparado como para uno es hueva de mirar los mismos centros de rehabilitación y las casas del Sename y es como entrar a una cárcel más chica no mas... Los drogadictos tenemos otra sensibilidad para ver las cosas, el drogadicto ve desde otra perspectiva, somos más pesimistas, vemos las cosas con más rechazo...

(Poblador, 37 años)

Cabe preguntarse ¿Por qué esta sensibilidad no es palpada por la episteme dominante cuando aborda el problema de la drogadicción o será que está muy arraigado en este régimen de verdad, la mirada de forma de las cosas, solo en el discurso externo y hacia afuera? porque en lo que respecta al discurso subterráneo, el de lo que verdaderamente se hace, las sensibilidades propias de estos individuos estarían desbordando, lo que Norbert Elías denominó como modelo y pautas de control de emociones correspondientes a su clase social. Dicho de una manera más sutil, la estructura emocional de estos sujetos, es decir de disconformidad hacia un sistema que 


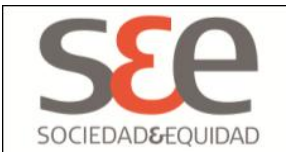

históricamente les ha sido hostil, rebasa por completo lo medianamente tolerable por el grupo dominante, ya que las necesidades, tanto espirituales como materiales, de los jóvenes drogadictos marginales, jamás podrían ser complacidas, siendo de este modo la episteme de los drogadictos marginales una verdad que transita por la vereda de al frente del "orden del discurso".

Norbert Elías explica en forma muy acabada en su obra El Proceso de la civilización (1998) la forma bajo la cual se construye el concepto de lo que es civilizado y lo que no lo es, a través de un largo proceso de cambio, de control de las emociones de los individuos y de adecuación de las sensibilidades de los mismos. En esta transformación de los modos del hombre occidental se habrían sentado las bases de cómo la civilización se alza por sobre la cultura, absorbiendo a esta última, sometiéndola o destruyéndola e intentando construir una cultura hegemónica a la medida de la clase dominante. Así, los jóvenes drogadictos marginales, con su existencia son una prueba de que este proceso civilizador es una constante en el devenir del hombre occidental, siendo víctimas de violencia simbólica todos aquellos sujetos que se opongan a sus rituales.

Dentro del proceso de modernización, llevado a cabo por la dictadura y continuado por los gobiernos de la concertación, la "reproducción cultural", ha jugado un papel estelar en la concepción de sujetos con conductas de desadaptación al orden instituido, ya que si bien desde el seno de éste, se transmiten, en su discurso externo y hacia afuera, voces de igualdad de condiciones y de oportunidades para todos los integrantes de una misma sociedad, en la realidad la adecuación al sistema cultural dominante va a depender exclusivamente de lo que Pierre Bourdieu denomina "la mirada". Con respecto a este concepto, el autor francés alude que; "La mirada es un producto de la historia reproducida por la educación" (Bourdieu, 1965). Entonces no es descabellado pensar que un sujeto que se ha formado en un grupo social favorecido por el sistema le fuese más fácil la adecuación a éste, existiendo concordancia entre su discurso personal y el discurso del sistema, por lo que no tendría mayores reparos en lo que a su funcionamiento y estructura se refiere. En cambio, un individuo cuyo origen radica en un sector perjudicado por el sistema tendrá una difícil adecuación al mismo y en caso de no lograrlo o de no querer hacerlo su discurso será antisistémico. "La pura mirada implica un rompimiento con la actitud ordinaria hacia el mundo, la cual, dadas las condiciones en las que ésta es llevada a cabo, es también una separación social" (Bourdieu, 1965). En este contexto, la mirada de los jóvenes drogadictos "hijos de la dictadura", está forjada desde un horizonte de derrota, en el cual el único espacio de educación (las jornadas de movilización y protesta de los '80), popular por cierto, fue apabullado no por quienes ellos creían era su enemigo (la dictadura), sino más bien por lo que ellos más anhelaban (la democracia). Para ellos, en un abrir y cerrar de ojos, el sueño se había convertido en pesadilla, y en ese escenario no fue nada extraño que buscaran la evasión por medio de la droga y del desenfreno. El problema fue que "el vehículo" escogido para rehuir de este mal sueño noventero, se transformó al poco andar, en una pesadilla.

Yo intente muchas veces nadar contra la corriente, por lo mismo, con hartos más, ahora siento un vacío en mi vida, no lo puedo suplir con nada, todos los vacíos no se pueden llenar, y ese vacío es constante, la droga es un calmante nomas, la droga ya llega un momento en que te hace sentir como las huevas, te hace sentir muy mal pero la necesitai, sí, la necesitai y podí estar sin ella, pero llega otro y aunque no queraí si hay otro consumiendo, consumí y estai consumiendo por el solo hecho de consumir. A mí como drogadicto solo me queda por 


\section{S\&e}

hacer, drogarme, volarme, no tengo más expectativas, me siento solo, el vacío de la droga te menoscaba, psicológica y físicamente te hace mierda, te hace mierda... es lo que elegí realmente, porque la mierda de sistema tampoco ofrecía algo mejor...

(Poblador, 37 años)

La Congoja de los jóvenes drogadictos "hijos de la dictadura", se ha fraguado a partir de la desobediencia a la sumisión de sus cuerpos y en su sedición a la conversión de su persona en "hombre - máquina" (utilizando el término acuñado por Michel Foucault). "A estos métodos que permiten el control minucioso de las operaciones del cuerpo, que garantizan la sujeción constante de sus fuerzas y les imponen una relación de docilidad - utilidad, es a lo que se puede llamar "disciplinas" (Foucault, 2002: 141). Pero ¿cómo se consigue disciplinar a un individuo que es en esencia díscolo al sistema? La réplica entregada por los drogadictos es una terminante y definitiva negativa a este estilo de dominación y funcionalización; es más, ellos rehúyen de su discordancia con el régimen de verdad, haciendo de sus organismos el receptáculo en el cual vacían toda su rabia y su frustración y tal vez sea que al no poder destruir y alterar el sistema que los ha postergado hayan resuelto inmolarse ellos mismos. ¡Peligrosa disposición! ésta tomada por los jóvenes drogadictos marginales, puesto que no pudiendo ser "fabricados", sometidos y adiestrados en función del sistema y la "economía nación", sí han doblado las rodillas y agachado sus cabezas ante el poder de sometimiento de la droga.

Yo toque harto tiempo en las micros pa fomentarme mis vicios... he tenido hartos amigos muertos, balas, por lo mismo por ir a comprar droga, ...a mí los pacos me han pegado hartas veces, comprando yo droga, yo los veo y la escondo, me he comido hartas veces droga, falopa, pasta, hasta pitos me he comido, la pata en el cuello, el paco te tira al suelo y te pone la pata en el cuello, bótala conchadetumadre empieza, ite saca la chucha! A mí cuantas veces no me ha pasado po... pero yo no soy delincuente, soy drogadicto, ino soy delincuente! Delincuente es el que anda robando y hay delincuente de corbata que salen todos los días en la tele, iesos son delincuentes!... nunca he robado, eso no va conmigo, he vendido todo eso sí, me compraba una cosa un día me pagaban, la vendía en la noche pa consumir, trabajaba, la compraba de nuevo y al otro día la vendía de nuevo, después te sentí pésimo, pésimo, inclusive en el momento que estaí consumiendo te sentí mal, taí con la bala pasada de puta que la cague y vamos fumando y vamos volándonos... mi drogadicción ahora no la disfruto, bueno solo mientras me dura la volada, pero yo igual estoy consciente de que estoy pa la cagada, y no puedo hacer nada, no se puede, no se puede, tengo 24 años de consumo es toda una vida, ini Maradona po huevón!, ini Diego!, pa salir tení que cambiar radicalmente, yo me hice hombre bajo el sistema de la droga, del consumo de droga, pa mí 


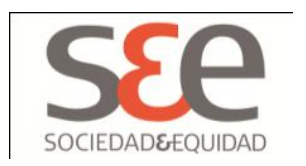

ser drogo era ser el más choro, yo fui uno de los primeros drogadictos de mi grupo de cabros chicos...

(Poblador, 37 años)

Aquí subyace la "episteme $e^{3}$ de los drogadictos marginales", no disciplinados por el sistema, pero sí por su adicción, no dispuestos al funcionalismo económico impuesto a través del "régimen de verdad", pero bien orientados a producir para saciar su ansia por las drogas.

Su gran contrariedad reside en que si bien se han redimido del disciplinamiento del cuerpo solicitado por el sistema para adecuarse a él, han quedado sometidos y atrapados también por su propia realidad; la de obedecer y doblegarse ante sus propios deseos, apetitos inextinguibles que viniendo desde el interior de su propio cuerpo no pueden ser vencidos, ni dominados por su dictamen. Pese a ello existe conciencia por parte de los individuos de esta peculiar cultura de pertenecer a otro sistema de vida, uno que se mueve por los márgenes de la legalidad y en constante contradicción con los aparatos de vigilancia policial, intentando, por esta misma razón, de escabullirse de "El panóptico";

Este espacio cerrado, recortado, vigilado, en todos sus puntos, en el que los individuos están insertos en un lugar fijo, en el que los menores movimientos se hallan controlados, en el que todos los acontecimientos están registrados, en el que un trabajo ininterrumpido de escritura une el centro y la periferia, en el que el poder se ejerce por entero, de acuerdo con una figura jerárquica continua, en el que cada individuo está constantemente localizado, examinado y distribuido entre los vivos, los enfermos y los muertos - todo esto constituye un modelo compacto del dispositivo disciplinario

(Foucault, 2002, 201).

Michel Foucault advertía cómo en el siglo XVIII la peste era utilizada como un subterfugio por el poder, para así mantener controlada a la población a manera de pretexto de un posible contagio de ésta. En el Santiago de la década de los noventa, la argucia empleada para observar e intervenir si es necesario a los individuos es la drogadicción, y es en las poblaciones marginales en donde hay que Vigilar y Castigar (Foucault, 2002), patrullar todas las calles peligrosas por donde puedan merodear estos "leprosos modernos", allanarlos buscando evidencia de su quebrantamiento al orden instituido, encerrándolos si es necesario, aislándolos de los saludables, para evitar el contagio. $Y$ este es el juego proyectado por los drogadictos: esconderse y burlar el poder omnipresente de las autoridades, mantenerse ocultos a la contemplación omnisciente y panóptica del sistema, intentando eludir la reclusión esbozada para ellos, sea esta la cárcel o el centro de rehabilitación.

\footnotetext{
3 "Foucault concebía los sistemas clasificatorios, "epistemes" o "regímenes de verdad", como él los llamaba, como expresiones de una determinada cultura y, al mismo tiempo, fuerzas que conforman dicha cultura."(Burke, 2006: 75).
} 


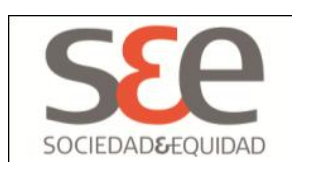

Yo en la década de los ochenta era bien niño todavía, y como nunca había vivido en democracia pensaba que toda la oposición al gobierno militar era un solo bando político, en cierta forma creí en este mundo en colores que nos prometían los políticos que más tarde nos gobernarían. Por lo mismo participe activamente de las concentraciones del NO para el plebiscito del año 1988, panfletee, tire hartas piedras y raye murallas. Cuando llego la democracia ese mundo del arco iris prometido jamás llego. Después entre a la Universidad y ahí seguí siendo oposición, me encapuchaba, pero ya sabía que ningún cambio lograría, luego me sumergí en un consumo de alcohol y drogas que fue paulatinamente creciendo hasta convertirme en un drogadicto problemático. En este punto de mi vida los ideales estaban sepultados, jamás obtuve justicia por mi padre, exonerado en 1973 por comunista, alcohólico durante toda la dictadura por pena o debilidad tal vez y fallecido a los 44 años de edad cuando recién se iniciaba la democracia. Al final volqué toda mi rabia y mi frustración en contra de mi persona y de mi entorno más cercano, y termine mal, me drogaba y me metía en problemas constantemente, muchas veces estuve detenido y a finales de los '90 estaba solo ya nadie me bancaba y al comenzar el nuevo milenio era prácticamente un indigente...

En el centro de rehabilitación... nunca fui educador, ni termine el tratamiento, ni en él me examino nunca un psicólogo o psiquiatra, era un ambiente bien incompatible con un tipo que ha sido dañado por el sistema. Al tiempo después me trato un especialista apelando más a mis problemas emocionales, más que mal la cagada en mi vida tenía que ver con el pasado, con mis vivencias. De los muchachos que conocí en el tratamiento solo uno está bien, los otros todos recaídos, drogándose, otros tantos presos y algunos hasta muertos. Ahora llevo años bien, pero la pena la decepción y la rabia aún afloran de vez en cuando...

\section{(Poblador, 37 años)}

En los centros de rehabilitación, más que solucionar las dolencias que aquejan a los drogadictos marginales lo que se busca es su disciplinamiento y funcionalización con el orden establecido. El método para lograr este objetivo es la vigilancia extrema y el control del discurso del adicto, hacerlo creer que en él radica el problema y eximir de toda responsabilidad al sistema. En cierta manera estas comunidades reproducen el sistema en pequeña escala, intensificando sus técnicas, conteniendo también un discurso externo benevolente hacia afuera (el de la rehabilitación) y uno interno hacia adentro (el que destruye y crea un hombre nuevo funcional al sistema), controlando las practicas discursivas de sus internos, mediante la disciplina ("La disciplina es un principio de control de la producción del discurso") (Foucault, 1992: 31) e intentando silenciar para siempre su propia episteme. 


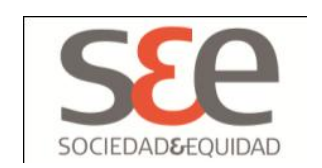

\section{Conclusiones}

En las poblaciones del Santiago de Chile de las últimas dos décadas del siglo XX se ha moldeado una particular cultura, la de los "jóvenes drogadictos marginales hijos de la dictadura", los cuales nacidos en el régimen militar se constituyeron como sujetos adaptados al discurso de rebeldía y esperanza, forjado en la lucha callejera llevada a cabo en el seno de sus poblaciones en contra del gobierno militar. De esta manera la violencia explícita aplicada por la dictadura tuvo como efecto un sentimiento de utilidad y una gran muestra de funcionalidad ante la realidad existente en la década de los ' 80 .

Este discurso insurreccional se vio suprimido por el pacto político llevado a cabo entre la clase mesocrática y los personeros de la dictadura militar que derivo en la llamada transición a la democracia.

Una vez reinstaurada la institucionalidad democrática los jóvenes pobladores que no lograron adaptarse a ella generaron conductas anomicas incurriendo muchos de ellos en el consumo abusivo de sustancias ilícitas.

En cierto modo los jóvenes drogadictos marginales se mantienen rebeldes al sistema durante toda la década de los noventa, creando una episteme propia, abiertamente enfrentada al régimen de verdad creado a partir del discurso oficial concertacionista que los tacho de delincuentes ante la opinión pública creando tres instancias para dominarlos; el control policial, el control psiquiátrico y la penalización de sus faltas (consumo de drogas). Así el empleo de violencia simbólica sobre los drogadictos "hijos de la dictadura" dejo al descubierto toda su disfuncionalidad y desadaptación a la nueva realidad. En definitiva esta nueva realidad era poseedora de mecanismos más finos de disciplinamiento no dejando espacios para la creación de ningún contradiscurso.

En conclusión, los drogadictos hijos de la dictadura estando habituados y dispuestos a contestar la represión y coacción de la dictadura con violencia explícita, se curtieron exclusivamente en este proceder de dialogo político, por ello una vez suprimido y deslegitimado el mismo no supieron responder de ninguna otra manera a la imposición del discurso creado a raíz del acuerdo dictadura - mesocracia rebelándose al nuevo contexto con la evasión mediante la ingesta desenfrenada de drogas y volcando toda esa violencia, de la que antes era objeto el sistema, en contra de sí mismos. 


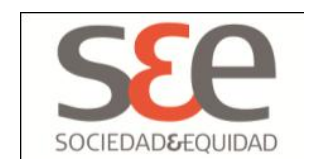

\section{Referencias Bibliográficas}

Auth, José (1988), Esperando a la esperanza. Los jóvenes y el plebiscito. Proposiciones Vol.16. Santiago: Ediciones SUR.

Bourdieu, Pierre (1999) Contrafuegos. Reflexiones para servir a la resistencia contra la invasión neoliberal. Barcelona: Anagrama.

Bourdieu, Pierre (1988) Introducción. La distinción. Criterios y bases sociales del gusto. Traducción a cargo de Óscar Martínez Gómez. Universidad Nacional Autónoma de México. Facultad de Ciencias Políticas y Sociales / Sociología. P. Traducción hecha a partir de la versión electrónica inglesa publicada por sociología. Disponible desde internet en: <http://www.forumglobal.de/soc/bibliot/b/bsocialcrit.htm>

Burke, Peter (2006) ¿Qué es la historia cultural? Barcelona, Editorial Paidós.

Elias, Norbert (1988) El proceso de la civilización. Investigaciones sociogenéticas y psicogenéticas. México: Fondo de Cultura Económica.

Enzensberger, Hans Magnus (2007) El perdedor radical. Ensayo sobre los hombres del terror. Barcelona: Editorial Anagrama.

Foucault, Michel (1992) El Orden del discurso. Buenos Aires: Tusquets Editores.

Foucault, Michel (2002) Vigilar y castigar: nacimiento de la prisión. Buenos Aires: Siglo XXI Editores.

Garcés, Mario (2002) Recreando el pasado: Guía metodológica para la memoria y la historia oral. Santiago de Chile: Eco Educación y Comunicaciones.

González Calleja, Eduardo (2003) La Violencia en la Política. Perspectivas teóricas sobre el empleo deliberado de la fuerza en los conflictos del poder. España: Consejo Superior de Investigaciones Científicas.

Instituto Nacional de Estadísticas (2001) Anuario de Estadísticas Policiales 2000. Departamento de Servicios al Usuario y Difusión, Santiago de Chile.

Martínez, Ernesto (2010), Poblador drogadicto de la comuna de El Bosque. 37 años.

Merton, Robert K. (2002) La división del trabajo social de Durkheim. Revista Española de Investigaciones Sociológicas, № 99, julio - septiembre.

Miguel (2010) joven de la población El Silo, 36 años.

Pérez, Cristián; Sepúlveda, Mauricio; Gaínza, Alvaro (1997) "La Angustia. Historias y discurso de jóvenes consumidores de pasta base de cocaína de la Zona Sur de Santiago (Primera parte)". En Gaínza, Álvaro [et al.], Futuro y Angustia. La juventud popular y la pasta base de cocaína en Chile. Santiago de Chile: Ediciones SUR; 1a edición.

Joven poblador (reserva de identidad) (2010), Poblador de la comuna de El Bosque. 37 años. 


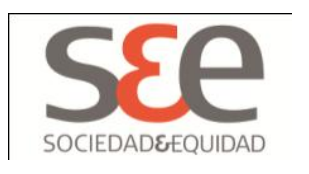

Salazar, Gabriel (1995) Del modelo neoliberal en Chile: La difícil integración entre los pobres los intelectuales y el poder (1989-1995). Santiago: Editorial Pas.

Salazar, Gabriel (2006) La Violencia Política Popular en las "Grandes Alamedas". La violencia en Chile 1947-1987 (una perspectiva histórico popular). Santiago: LOM Ediciones.

Salazar, Gabriel y Pinto, Julio (1999) Historia contemporánea de Chile, Vol. II Actores, identidad y movimiento. Santiago: LOM Ediciones.

Salazar, Gabriel y Pinto, Julio (2002) Historia Contemporánea de Chile, Vol. V Niñez y juventud. Santiago: LOM Ediciones.

Tironi, Eugenio (1987), Marginalidad, movimientos sociales y democracia. Proposiciones 14. Santiago: Ediciones SUR.

Wacquant, Loïc (2001) Parias urbanos. Marginalidad en la ciudad a comienzos del milenio. Buenos Aires: Manantial.

Aylwin, Patricio (1990) Discurso dado en el Estadio Nacional en: <http://www.museodeprensa.cl/1990/discurso-de-patricio-aylwin-en-el-estadio-nacional>

Aylwin, Patricio (1990) Discurso dado en el Estadio Nacional en:<http://www.archivo-chile.com> 